\section{On laterality of visual aftereffects: $A$ rejoinder}

\author{
VINCENT DI LOLLO \\ University of Alberta, Edmonton, Alberta, Canada
}

Temporal integration of a dot matrix whose elements are displayed in rapid temporal sequence can be achieved easily, provided that all dots are plotted within a critical temporal interval. The duration of the critical interval is the same whether the stimuli are displayed in the left visual field or in the right visual field (Di Lollo, 1981). These results suggest that duration of visible persistence (restrictively defined as in that article) is probably the same in both cerebral hemispheres.

In a commentary on these findings, Wurst and Long (1983) take exception to the inference of hemispheric symmetry in duration of visible persistence because: "To conclude from one task under one set of stimulus conditions that persistence is not lateralized is presumptuous at best"' (p. 595). Here, a brief attempt shall be made at mitigating Wurst and Long's disapprobation. Closer attention will then be paid to more salient issues regarding visible persistence.

At the basis of Wurst and Long's critique is the belief that, from the results reported in 1981 , "Di Lollo concluded that the issue of laterality and visual persistence was resolved"' (p. 595). In fact, no such sweeping conclusion is either stated or implied in that article. Besides, a reading of the complete context shows that what the article set out to "resolve" was an inconsistency among several sets of experimental data, more so than the issue of lateralization of visible persistence. I do not believe that this sort of issue can be settled in a single study.

Were this the sole source of misunderstanding, Wurst and Long's critique would hardly require comment. But there is a more general aspect of the critique that deserves attention, for it harks to the definition of the very phenomenon under study. Throughout the article in question (Di Lollo, 1981), a careful distinction was drawn between visible persistence and other nonvisible aftereffects of visual stimulation. To quote, it was stressed that "it is necessary to distinguish between visible and nonvisible forms of sensory persistence. Such separation is akin to Sperling's (1967) distinction between

Preparation of this article was supported by Grant A6592 from the Natural Sciences and Engineering Research Council of Canada. I would like to thank Peter F. Dixon for commenting on an earlier draft of this article. Requests for reprints should be sent to Vincent Di Lollo, Department of Psychology, University of Alberta, Edmonton, Alberta T6G 2E9, Canada. visible and nonvisible memory traces, and parallels the distinction made by Phillips (1974) and by Turvey (1978) between visible and schematic persistence. While the former is an immediate and short-lived visible image of the display, the latter is said to occur at further processing stages. Although arising from visual stimulation and still maintaining some structural information about the display, schematic persistence is held to be no longer visible'" (Di Lollo, 1981 , pp. 21-22; italics in the original). Such distinction was fundamental to the argument of the article, which was that lateralized effects probably arise only at advanced stages of processing, characterized by nonvisible (schematic) forms of stimulus coding. But the distinction was not noted by Wurst and Long. As a consequence, their critique was pitched at a definitional level that ignored not only the explicitly stated boundaries of the phenomenon under investigation, but also the conceptual advances of Coltheart (1980), Phillips (1974), and Turvey (1978), among others.

Mismatch of definitional terms holds potentially confusing consequences. It is with a view to forestalling untoward developments that we now examine some of the more common definitional problems and their consequences.

\section{Development of a Definition}

Presentation of a brief visual stimulus produces a range of visual aftereffects, some visible, others nonvisible. Despite Sperling's (1967) careful separation of visible from nonvisible memory traces, the distinction between them was often ignored, and several aftereffects of visual stimulation came to be lumped under the rubric of "iconic memory." The icon was regarded as a faithful, rapidly fading picture lingering in the visual system after the termination of the inducing stimulus. Duration of the icon was most commonly placed at about $250 \mathrm{msec}$, although durations as long as $10 \mathrm{sec}$ have been suggested (e.g., Sakitt, 1976).

It soon became apparent, however, that a blanket notion of the icon as an entirely visible representation was untenable for a variety of reasons. These reasons need not be reviewed here because they have been discussed repeatedly elsewhere (e.g., Coltheart, 1980; Di Lollo, 1977; Phillips, 1974). Perhaps the most thorough treatment of this topic has been provided by Turvey (1978, particularly pp. 101-120). The weight of the evidence marshaled by Turvey points to the necessity of subdividing what was globally known as "iconic memory" into at least two components: an initial, brief, visible aftereffect and a somewhat more durable, but nonvisible, aftereffect. Phillips (1974) estimated the duration of 
the visible component at about $100 \mathrm{msec}$, and that of the nonvisible (schematic) component at $600 \mathrm{msec}$ or longer.

Visible and nonvisible aftereffects were found to differ not only in temporal extent, but also in capacity, susceptibility to masking, and, probably, locus within the visual system. Turvey (1978) regards one as being visible, brief, susceptible to masking, of indefinitely large capacity, and tied to a fixed (probably retinotopic) position. By contrast, he regards the other as nonvisible, temporally substantial, nonmaskable, of limited capacity, and not tied to a fixed retinotopic position.

As a consequence of these developments, terms such as "icon," "iconic memory," and the more generic "visual persistence" - which were unambiguous in their earlier definitions (Neisser, 1967)became ambiguous in that they did not convey the distinction between visible and nonvisible aftereffects of visual stimulation. At least three authors (Coltheart, 1980; Phillips, 1974; Turvey, 1978) coined new terms and redefined others (albeit in somewhat inconsistent and sometimes contradictory fashion) to distinguish between the two components and to denote them separately. Coltheart (1980), in particular, was adamant in his rejection of the term "visual persistence" as being entirely ambiguous and holding potentially chaotic consequences. Specifically, he pointed out that the term "visual persistence" could refer indifferently either to visible persistence whose "sine qua non ... is that it can be seen" (Coltheart, 1980, p. 185; italics Coltheart's) or to informational persistence, akin to Phillips's (1974) concept of "schematic" persistence, and not necessarily visible.

Despite all this, the term "visual persistence" continues to be in common usage by Long and his co-workers (e.g., Wurst \& Long, 1983). To be sure, in deference to Coltheart's arguments, Long and Gildea (1981) did discuss the meaning of the term as follows: "To what phenomenon, or class of phenomena, should the common phrase 'visual persistence' be applied? Currently it is used in its broadest sense to refer to any form of post-stimulus visual phenomena assessed on a wide variety of very different tasks" (p. 399). Later in the same paragraph, an additional definition is given as "the total phenomenal extent of a brief target." But the crucial question remains: Does the term "visual persistence," as used by Long and co-workers, refer to visible persistence or to nonvisible "schematic" persistence? From Long and Gildea's definitions it is impossible to say. It probably refers to both. Indeed, Turvey (1978, particularly pp. 118-120) has adduced compelling evidence to show that total phenomenal duration of a brief target includes both visible persistence and schematic persistence.
Referring to two separate phenomena with a single term has more than semantic implications. To paraphrase Coltheart $(1980$, p. 207 , having tendered due apologies), if we have a visual aftereffect $\mathbf{X}$ (visible, brief, maskable, etc.) and another visual aftereffect $Y$ (nonvisible, temporally substantial, nonmaskable, etc.), then we can call process $X$ "visual persistence" and process $Y$ something else, or call process $Y$ "visual persistence" and process $X$ something else. What we cannot do without creating the utmost chaos is to use the term "visual persistence" to refer both to $X$ and to $Y$ if it is indeed the case that $X$ and $Y$ are different things.

Despite the evidence adduced by other researchers, Wurst and Long have maintained the practice of not distinguishing between visible and nonvisible persistence. And that may well be their prerogative. But then, through ambiguous usage of the term "visual persistence," they ascribe the same practice to others (e.g., Di Lollo, 1981) and proceed to criticize instances of noncompliance with the imputed definition. And that, by most canons, is not their prerogative. As a splendid example of how the ambiguous term is foisted on others, reconsider the earlier quote in which Wurst and Long impute that I opine that "the issue of laterality and visual persistence was resolved" (p. 595; italics added). Of course, the term "visual persistence" never appeared in the paper in question (Di Lollo, 1981). What is more, the argument of the paper was based on a clear and unambiguous rejection of just the type of global definition assigned to that term by Long and Gildea (1981).

We now turn to some of the consequences that ensue from using ambiguous terminology.

\section{Adequate Stimuli}

Wurst and Long (1983) state: "Other methodological considerations that $\mathrm{Di}$ Lollo failed to address are stimulus factors such as the verbal/nonverbal nature of the stimulus and the complexity of the stimulus" (p. 596; italics in the original).

Particularly puzzling is the complaint regarding verbal/nonverbal stimuli. At the outset of the article in question (Di Lollo, 1981), the suitability of verbal stimuli is discussed with reference to the work of Erwin and Nebes (Note 1), who employed a verbal task and obtained evidence of lateralization in duration of "visual persistence." It is stressed that the duration of the aftereffects studied by Erwin and Nebes could not be ascribed unambiguously to visible persistence. This is so because the verbal task could be accomplished without the requirement that the stimuli remain visible. Di Lollo (1981) also stressed that "an alternative account of these results would be that the letters in the display might have remained visible for an equal amount of time 
in both hemispheres, but that unequal additional time was taken after the termination of visible persistence to decode and interpret the contents of the display. On this option, Erwin and Nebes's results would be attributable not to hemispheric differences in duration of visible persistence but to hemispheric asymmetries in the duration of higher processes taking place after the termination of visible persistence" (p. 21).

This is the same argument made and documented by Turvey (1978) along virtually identical lines of reasoning. It explains why it is not possible to study visible persistence (let alone its lateralization) with verbal tasks that can still be performed when the stimulus configuration is no longer perceptually available. But Wurst and Long apparently misinterpreted the argument. To repeat: nobody disputes that verbal/nonverbal issues must be examined in order to arrive at a full description of laterality of function. What cannot be done is to study lateralization of visible persistence using tasks or stimuli that do not produce unequivocal estimates of visible persistence in the first place. Yet, with their insistence on a unitary definition of visual aftereffects, this is just what Wurst and Long suggest that we do.

Next, let us attend to Wurst and Long's concern that stimulus complexity was a "seriously overlooked factor" in the investigation.

Wurst and Long cite results suggesting that magnitude of hemispheric asymmetries in duration of "visual persistence" depends on level of stimulus complexity. Those results, however, were obtained with tasks that were not selectively sensitive to one or the other forms of persistence in that they could be performed on the basis of nonvisible, as well as visible, aftereffects.

Indeed, contrary to Wurst and Long's conclusions, there are strong and valid reasons for believing that the effects of stimulus complexity are confined entirely to schematic persistence. In a series of studies designed to examine the effects of stimulus complexity on short-term visual aftereffects, Phillips (1974) demonstrated that visible persistence was entirely unaffected even by large changes in level of stimulus complexity. By contrast, the longer lasting, nonvisible, schematic persistence was highly sensitive to variations in stimulus complexity. Thus, stimulus complexity affected schematic persistence but not visible persistence. For a lengthier evaluation of Phillips' experiments and of the role of stimulus complexity in visible and in nonvisible persistence, see Turvey (1978, particularly p. 111).

Again, nobody disputes that complexity is a stimulus dimension pertinent to the study of laterality. But, until Phillips's (1974) results are disconfirmed, complexity remains a dimension irrelevant to the study of visible persistence, whether in one cerebral hemisphere or in two. The confusion arises once again from failure to distinguish visible from nonvisible aftereffects of stimulation.

Not to belabor a point, we shall overlook similarly misdirected "serious questions" raised by Wurst and Long in their critique. Instead, we shall move on to the issue of Type I and Type II persistence, an issue that, as has been pointedly noted by Wurst and Long, was not raised in the article on laterality (Di Lollo, 1981).

\section{Two Types of Measures}

Hawkins and Shulman (1979) introduced the terms "Type I" and "Type II" to denote separate procedures that had been used to examine duration of the "sensory residual" following brief visual displays. The concept of "sensory residual" does not distinguish visible from schematic persistence. However, since such distinction is not required in the following discussion, we shall follow suit and employ the term "sensory residual" to designate the combination of visible and schematic persistence.

Hawkins and Shulman (1979) noted that most investigations of visual sensory residuals could be separated into two classes, according to the type of judgment that the observers were required to make. In one class of studies (Type I), the observers were required to detect the earliest possible indication that the inducing stimulus had been turned off. To do this, they were to respond to the minimum detectable decrement in strength of sensory residual, suggestive of the termination of the inducing stimulus, regardless of whether the sensory residual was still perceptually available. A moment's reflection will show that, in the Type I tasks, the observers estimated not the total duration of the sensory residual, but the rate at which it decayed. To wit, if a given decrement in strength can be detected over a briefer temporal interval for residual $X$ than for residual $\mathrm{Y}$, then residual $\mathrm{X}$ is decaying at the faster rate. In the second class of studies (Type II), duration of sensory residual was estimated by requiring the observers to indicate when all traces of the sensory residual had subsided (not just when its strength had diminished perceptibly). Studies of Type II, therefore, were direct estimates of the total duration of the sensory residual.

The point to be noted is that, as employed by Hawkins and Shulman (1979), the terms "Type I" and "Type II" refer to different ways of measuring the sensory residual, not to qualitatively different kinds of residuals.

Departing from this state of affairs, Long set out to "extend Hawkins and Shulman's proposals" (Long, 1979, p. 412) by redefining the two terms as referring to separately identifiable visual processes. In Long's extension, "Type I" persistence refers to the latency of visual off responses, and 
"Type II" refers to persistence produced by prolonged photoreceptor activity. On the face of it, this could be a bold, imaginative step, provided that strong logical and empirical links were forged between Hawkins and Shulman's initial definitions and assumptions on the one hand, and the definitions and assumptions underlying Long's extensions on the other. Unless this is done, the term "Type I" (or "Type II") would refer ambiguously to different things.

Long (1979) attempted to provide some common ground between the two sets of definitions by noting that latency of the off response is known to be inversely related to stimulus energy, while duration of photoreceptor activity is known to be directly related to stimulus energy. The same energy relationships had been postulated by Hawkins and Shulman for Type I and Type II measures, respectively. But this is hardly sufficient for establishing that Hawkins and Shulman's terms and Long's terms refer to the same class of events. Indeed, there is clear evidence that they do not.

Consider the term "Type I persistence." Long claims that, in his own definition, as in Hawkins and Shulman's, it refers to latency for the perceived termination of a stimulus. To this extent, the two definitions coincide. But Long's further claim that "Type I persistence" corresponds to the latency of the off response deviates sharply from Hawkins and Shulman's proposals. In Hawkins and Shulman's views, latency for perceived offset is merely an index of the rate at which the sensory residual is decaying. On this formulation, Type I measures of the sensory residual may be taken at any point throughout the time course of the decay function, not only at its inception. To clarify, imagine that it were possible to conduct an experiment with the following instructions to a hypothetical superobserver: "Adopt as your baseline the level of brightness to which the sensory residual has decayed $200 \mathrm{msec}$ [any other value smaller than the total duration of the sensory residual could be used here] after you first noticed that the stimulus had been turned off. Then indicate [in some way] as soon as you detect a decrement in brightness from that level."

In Hawkins and Shulman's (1979) terms, this experiment would make perfectly good sense. In fact, were we to accept Sakitt's (1976) 10-sec estimate of the duration of sensory residuals, this experiment could be easily performed. But it would make little sense to conclude that every perceivable decrement throughout the course of decay of the sensory residual generates a separate off response in the observer's visual system, as Long's (1979) definition of Type I persistence would lead us to expect.

Long's and Hawkins and Shulman's conceptions of Type I effects differ widely in this, as well as in other important respects. Yet, Long continues to use the term (e.g., Wurst \& Long, 1983) without specifying which of the two meanings he wishes to assign to it. It would be helpful if Long would either establish unequivocal compatibility between Hawkins and Shulman's and his own definition of the term "Type I" or, in deference to priority, call his own something else.

As for "Type II persistence," Long (1979) redefines it as actually consisting of two separate decaying "icons" (Long's term): one being produced by the cones, the other by the rods. This is a clearcut suggestion: let us examine how it relates to Hawkins and Shulman's usage of the same term.

Consider the sensory residual produced by the cones (or, if you wish, by the rods). According to Long (1979), the strength of this Type II residual declines over a period of time until it vanishes. In terms of Hawkins and Shulman's proposal, this sensory residual can be examined either in terms of its rate of decay (e.g., we could ask the observer to respond to a decrement in the strength of the residual at any point in time-a Type I measure) or in terms of its total duration (a Type II measure). Here, then, we have a case of Type II persistence that is both Type I and Type II (or something to that effect). This is the kind of confused outcome that ensues from using a single term to denote two different things.

In the same vein, the term "Type II persistence" now seems to refer not to two but to three different things. Namely, as used by Wurst and Long (1983), the designation "Type II" could refer either to what Long (1979) means by it or to what Hawkins and Shulman mean by it. Even a careful study of the context does not reveal the intended meaning. Let us assume that they are abiding by Long's own definition; but, even in this case, we still do not know whether reference is being made to persistence produced by the rods or by the cones. So, when Wurst and Long (1983) object that only one type of persistence was investigated in the work in question (Di Lollo, 1981), and that the other type should also be investigated, one is left wondering just what it is that they mean.

\section{Some Concluding Remarks}

A more general conceptual problem of Wurst and Long (1983) also bears mentioning. It illustrates the difficulties that can be encountered when one exceeds the boundaries of one's own definitions.

Persistence, according to Long, can be Type I or Type II. More specifically, persistence can be based on three processes: off responses, activation of the cones, and activation of the rods. All three processes are undeniably retinal. Bearing this in mind, let us examine Wurst and Long's (1983) statement that variables such as sex differences must be ex- 
amined before the issue of lateralization is considered settled. This is a worthwhile sentiment, with which one can hardly disagree. But how likely is it that off responses (or action of photoreceptors) in the hemiretinae corresponding to the left visual field differ from the off responses in the hemiretinae corresponding to the right visual field to a degree sufficient to produce lateral asymmetries in persistence? To my knowledge, no such differences have been reported in neuroanatomical or in neurophysiological investigations. Actually, to predicate sex differences in lateralization of persistence in terms of a retinal theory, we should expect to find relative sex differences in the functioning of the two pairs of hemiretinae: an intriguing, but hardly likely, prospect. It is unlikely that Long himself would expect to find such differences. Yet, this is the compelling implication of his definitions and arguments.

If one were so inclined, it would be possible to examine each remaining comment made by Wurst and Long to show how it arises from unclear or ambivalent usage of terms and concepts. But the examples detailed in the foregoing should suffice to make the point that if cooperative interchanges of the kind initiated by Wurst and Long are to succeed, it is imperative that clarity and unequivocalness of terms be maintained, and that extant results be evaluated within the bounds of the specified conceptual frameworks.

\section{REFERENCE NOTE}

1. Erwin, D. E., \& Nebes, R. D. Right hemispheric involvement in the functional properties of visual persistence. Paper presented at the annual meeting of the Eastern Psychological Association, New York, April 1976.

\section{REFERENCES}

Coltheart, M. Iconic memory and visible persistence. Perception \& Psychophysics, 1980, 27, 183-228.

Di LoLLo, V. On the spatio-temporal interactions of brief visual displays. In R. H. Day \& G. V. Stanley (Eds.), Studies in perception. Perth, Australia: University of Western Australia Press, 1977.

Di Lollo, V. Hemispheric symmetry in duration of visible persistence. Perception \& Psychophysics, 1981, 29, 21-25.

Hawkins, H. L., \& Shulman, G. L. Two definitions of persistence in visual perception. Perception \& Psychophysics, 1979, 25, 348-350.

Long, G. M. Comment on Hawkins and Shulman's Type I and Type II visual persistence. Perception \& Psychophysics, 1979 , 26, $412-414$.

Long, G. M., \& Gildea, T. J. Latency for the perceived offset of brief target gratings. Vision Research, 1981, 21, 1395-1399.

NeIsser, V. Cognitive psychology. New York: Appleton-CenturyCrofts, 1967.

Phillips, W. A. On the distinction between sensory storage and short-term visual memory. Perception \& Psychophysics, 1974, 16, 282-290.

SakitT, B. Iconic memory. Psychological Review, 1976, 83, 257-276.

Spenlina, G. Successive approximations to a model for shortterm memory. Acta Psychologica, 1967, 27, 285-292.

TurveY, M. T. Visual processing and short-term memory. In W. K. Estes (Ed.), Handbook of learning and cognitive processes (Vol. 5). Hillsdale, N.J: Erlbaum, 1978.

Wurst, S. A., \& Long, G. M. Laterality and visual persistence: Still a two-sided issue. Perception \& Psychophysics, 1983, 33, 595-598.

(Manuscript received February 14, 1983; accepted for publication February 14, 1983.) 